\title{
Diethylcarbamazine Attenuates the Development of Carrageenan-Induced Lung Injury in Mice
}

\author{
Edlene Lima Ribeiro, ${ }^{1,2}$ Karla Patricia de Souza Barbosa, ${ }^{1}$ Ingrid Tavares Fragoso, ${ }^{1}$ \\ Mariana Aragão Matos Donato, ${ }^{1}$ Fabiana Oliveira dos Santos Gomes, ${ }^{1}$ \\ Bruna Santos da Silva, ${ }^{1}$ Amanda Karolina Soares e Silva, ${ }^{1}$ Sura Wanessa Santos Rocha, ${ }^{1}$ \\ Valdemiro Amaro da Silva Junior, ${ }^{3}$ and Christina Alves Peixoto ${ }^{4}$ \\ ${ }^{1}$ Pós-Graduação em Ciências Biológicas da Universidade Federal de Pernambuco, Avenida Professor Moraes Rego, s/n, Cidade \\ Universitária, 50670-901 Recife, PE, Brazil \\ ${ }^{2}$ Instituto Aggeu Magalhães, FIOCRUZ, Avenida Professor Moraes Rego, s/n, Cidade Universitária, 50670-420 Recife, PE, Brazil \\ ${ }^{3}$ Departamento de Morfologia e Fisiologia Animal da Universidade Federal Rural de Pernambuco, Rua Dom Manoel de Medeiros, $s / n$, \\ Dois Irmãos, 52171-900 Recife, PE, Brazil \\ ${ }^{4}$ Laboratório de Ultraestrutura, Instituto Aggeu Magalhães, FIOCRUZ, Avenida Professor Moraes Rego, s/n, Cidade Universitária, \\ 50670-420 Recife, PE, Brazil
}

Correspondence should be addressed to Edlene Lima Ribeiro; edlenelimaribeiro@gmail.com

Received 19 July 2013; Accepted 3 December 2013; Published 16 January 2014

Academic Editor: Tânia Fröde

Copyright (C) 2014 Edlene Lima Ribeiro et al. This is an open access article distributed under the Creative Commons Attribution License, which permits unrestricted use, distribution, and reproduction in any medium, provided the original work is properly cited.

\begin{abstract}
Diethylcarbamazine (DEC) is an antifilarial drug with potent anti-inflammatory properties as a result of its interference with the metabolism of arachidonic acid. The aim of the present study was to evaluate the anti-inflammatory activity of DEC in a mouse model of acute inflammation (carrageenan-induced pleurisy). The injection of carrageenan into the pleural cavity induced the accumulation of fluid containing a large number of polymorphonuclear cells (PMNs) as well as infiltration of PMNs in lung tissues and increased production of nitrite and tumor necrosis factor- $\alpha$ and increased expression of interleukin- $1 \beta$, cyclooxygenase (COX2 ), and inducible nitric oxide synthase. Carrageenan also induced the expression of nuclear factor- $\kappa \mathrm{B}$. The oral administration of DEC $(50 \mathrm{mg} / \mathrm{Kg})$ three days prior to the carrageenan challenge led to a significant reduction in all inflammation markers. The present findings demonstrate that DEC is a potential drug for the treatment of acute lung inflammation.
\end{abstract}

\section{Introduction}

Since 1947, diethylcarbamazine citrate (DEC) has been used in the treatment and control of lymphatic filariasis, which is caused by the nematodes Wuchereria bancrofti, Brugia malayi, and B. timori, and is one of the drugs used in the Global Programme for the Elimination of Lymphatic Filariasis [1]. However, despite its long period of use, little is known regarding its mechanism of action.

Pharmacological studies have demonstrated that DEC affects the metabolism of arachidonic acid, thereby acting as an anti-inflammatory drug. Substantial evidence has demonstrated that DEC blocks a number of steps in both the cyclooxygenase (COX) and lipoxygenase pathways. This drug is a potent blocker of leukotriene production, and bronchial vasoconstrictor substances and also inhibits the production of prostaglandin (PGE2), prostacyclin (PGI2), and thromboxane A2 (TXA2) [2].

According to Mathews and Murphy (1982) [3], DEC inhibits the formation of $\mathrm{LTB}_{4}$ and sulfidopeptide leukotrienes, which are potent vaso/bronchoconstrictors, in mastocytomas, while stimulating the formation of 5-hydroxyeicosatetraenoic acid, suggesting that the site of action of DEC for inhibiting leukotrienes formation may be the leukotriene $\mathrm{A}_{4}$ synthetase reaction. Moreover, Bach and Brashler (1986) [4] found that DEC inhibited the formation of sulfidopeptide leukotrienes in rat basophil leukemia cells. 
Clinical studies have found that DEC is quite effective in the treatment of symptoms of bronchial asthma $[5,6]$. Recent studies carried out in cooperation with our laboratory demonstrated that DEC plays an important role in blocking pulmonary eosinophilic inflammation in mice sensitized with ovalbumin, effectively preventing the effects of subsequent airway resistance, Th1/Th2 cytokine production, pulmonary eosinophil accumulation, and eosinophilopoiesis both in vivo and ex vivo. Moreover, DEC directly suppressed interleukin-5-dependent eosinophilopoiesis in naive bone marrow [7].

Carrageenan-induced inflammation is a model of local acute inflammation commonly used to evaluate the activity of anti-inflammatory drugs [8] and assess the contribution of cells and mediators to the inflammatory process [9]. The inflammatory process is invariably characterized by the production of prostaglandin, leukotrienes, histamine, bradykinin, platelet-activating factor, interleukins (IL), and migrating cells [10]. The recruitment of polymorphonuclear cells (PMNs) from the circulation to the inflamed tissue has a key function in the breakdown and remodeling of injured tissue $[11,12]$. Moreover, macrophages participate in the progression of experimental pleurisy by producing proinflammatory cytokines, such as tumor necrosis factor- $\alpha$ (TNF $\alpha)$ and IL- $1 \beta$ [13]. The initial phase of carrageenan-induced acute inflammation ( 0 to $1 \mathrm{~h}$ ) not inhibited by nonsteroidal anti-inflammatory drugs, such as indomethacin, has been attributed to the release of histamine, 5-hydroxytryptamine, and bradykinin, followed by a late phase ( 1 to $6 \mathrm{~h}$ ), mainly sustained by prostaglandin release attributed to the induction of cyclooxygenase-2 (COX-2) [13, 14].

Considering the anti-inflammatory properties of DEC as a result of its effect on the metabolism of arachidonic acid, the purpose of the present study was to investigate the antiinflammatory action of this drug in a model of carrageenaninduced pleurisy $(4 \mathrm{~h})$, determining the following end points of the inflammatory response: (1) PMN infiltration; (2) lung injury (histology and ultrastructure); (3) expression of TNF$\alpha$ (ELISA and immunohistochemistry); (4) expression of IL-1 $\beta$, COX-2 (immunohistochemistry and western blot), nitric oxide synthase (iNOS) (immunohistochemistry), and nuclear factor- $\kappa \mathrm{B}$ p 65 (NFkB p65) (western blot); and (5) the synthesis of nitric oxide (NO) (nitrite concentration).

\section{Materials and Methods}

2.1. Animals. Male Swiss mice (weight: 20 to $25 \mathrm{~g}$; $\mathrm{CPqAM} / \mathrm{PE}$, Brazil) were used following institutionally approved protocols (CEUA\#LW-47/10). The animals were housed in a controlled environment and provided with standard rodent chow and water.

2.2. Experimental Groups. Mice were randomly allocated into the following groups:

(i) sham + water group: in which identical surgical procedures to the carrageenan group (CAR) were performed, but saline was administered instead of carrageenan (intrapleural) $(N=10)$; (ii) CAR + water group: mice subjected to carrageenaninduced pleurisy (intrapleural) $(N=10)$;

(iii) CAR + DEC group: mice subjected to carrageenaninduced pleurisy and diethylcarbamazine $(50 \mathrm{mg} / \mathrm{Kg}$, oral route) three days prior to the carrageenan challenge $(N=10)$;

(iv) CAR + INDO group: mice subjected to carrageenaninduced pleurisy and indomethacin $(5 \mathrm{mg} / \mathrm{Kg}$, oral route) three days prior to the carrageenan challenge $(N=10)$.

The therapeutic dose regimen for lymphatic filariasis recommended by the World Health Organization is $6 \mathrm{mg} / \mathrm{Kg}$ for 12 days [15]. As the total metabolism rate of mice is approximately seven times that of humans, $50 \mathrm{mg} / \mathrm{Kg}$ of DEC was adjusted according to the body weight [16]. The dose of indomethacin $(5 \mathrm{mg} / \mathrm{Kg})$ was based on a previous study [17].

2.3. Carrageenan-Induced Pleurisy. The mice were anesthetized with an intramuscular injection of a combination of $10 \%$ ketamine hydrochloride $(115 \mathrm{mg} / \mathrm{Kg})$ and $2 \%$ xylazine $(10 \mathrm{mg} / \mathrm{Kg})$. After confirmation of analgesia, the right side of the chest was shaven and either sterile saline or sterile saline containing $1 \% \lambda$-carrageenan $(0.1 \mathrm{~mL})$ was administered into the pleural cavity in the sixth intercostal space. Four hours after carrageenan injection, the animals were sacrificed through $\mathrm{CO}_{2}$ inhalation. The chest was carefully opened and the pleural cavity was rinsed with $1 \mathrm{~mL}$ of saline solution containing heparin $(5 \mathrm{U} / \mathrm{mL})$ [18]. The exudate and washing solution were removed by aspiration. Any exudate contaminated with blood was discarded. Samples of the fluid from the pleural cavity were collected to determine the total leukocyte content.

Total leukocytes were determined in a Neubauer chamber with the exudate diluted in Turk's solution $(1: 20)$ [17]. As the carrageenan-induced inflammatory response in the pleural space of mice has a biphasic profile, peaking at 4 and $48 \mathrm{~h}$ after pleurisy induction, the expression of inflammatory mediators was measured $4 \mathrm{~h}$ after the injection of carrageenan, based on previous studies [8].

2.4. Histological Examination. Lung base biopsies were performed $4 \mathrm{~h}$ after carrageenan injection. Lung fragments were washed twice in PBS, pH 7.2, and fixed in Bouin's solution (1\% saturated picric acid, formaldehyde, and $40 \%$ glacial acetic acid) for 8 hours, dehydrated in an increasing ethanol series, cleared in xylene, and embedded in purified paraffin (VETEC, São Paulo, SP, Brazil). Tissue sections of $5 \mu \mathrm{m}$ were cut using a microtome (Leica RM 2125RT), deparaffinized with xylene, stained with haematoxylin/eosin, and studied using light microscopy [19].

2.5. Electron Transmission Microscopy. The lung fragments were fixed overnight in a solution containing $2.5 \%$ glutaraldehyde and $4 \%$ paraformaldehyde in $0.1 \mathrm{M}$ cacodylate buffer. The samples were then washed twice in the same buffer and postfixed in a solution containing $1 \%$ osmium tetroxide, $2 \mathrm{mM}$ calcium chloride, and $0.8 \%$ potassium ferricyanide in 
0.1 M cacodylate buffer, $\mathrm{pH}$ 7.2, dehydrated in acetone, and embedded in Embed 812. Polymerization was performed at $60^{\circ} \mathrm{C}$ for three days [20]. Ultrathin sections were collected on 300-mesh nickel grids, counterstained with 5\% uranyl acetate and lead citrate, and examined using a FEI Morgani 268D transmission electron microscope.

2.6. Immunohistochemical Localization of $T N F-\alpha, I L-1 \beta$, $C O X-2$, and $i N O S$. Five sections ( $5 \mu \mathrm{m}$ in thickness) from each group were cut and adhered to slides treated with 3aminopropyltriethoxysilane (APES (Sigma, USA)). Briefly, sections were deparaffinized with xylene and rehydrated in graded ethanol (100 to $70 \%$ ). To minimize endogenous peroxidase activity, the slides were treated with $10 \%(\mathrm{v} / \mathrm{v})$ $\mathrm{H}_{2} \mathrm{O}_{2}$ in water for fifteen minutes. The sections were washed with $0.01 \mathrm{M}$ PBS ( $\mathrm{pH} 7.2$ ) and then blocked with $1 \%$ BSA, $0.2 \%$ Tween 20 in PBS for $1 \mathrm{~h}$ at room temperature. The sections were incubated overnight at $4^{\circ} \mathrm{C}$ with anti-TNF- $\alpha$ antibody (ABCAM, CA, USA, 1:250), anti-IL-1 $\beta$ antibody (GenWay, San Diego, CA, USA, 1:250), anti-COX-2 antibody (ABCAM, CA, USA, 1:400), and anti-iNOS (ABCAM, CA, USA, 1:50). The antigen-antibody reaction was visualized with avidin-biotin peroxidase (Dako Universal LSAB + Kit, Peroxidase), using 3,3-diaminobenzidine as the chromogen. The slides were counterstained with hematoxylin. Positive staining resulted in a brown reaction product. Five pictures at the same magnification were quantitatively analyzed using the Gimp 2.6 software program (GNU Image Manipulation Program, UNIX platforms).

2.7. Myeloperoxidase (MPO) Activity. MPO activity, an indicator of PMN accumulation, was determined as previously described [21]. Lung tissues were obtained and weighed, each piece homogenized in a solution containing $0.5 \%(\mathrm{w} / \mathrm{v})$ hexadecyltrimethylammonium bromide dissolved in $10 \mathrm{mM}$ potassium phosphate buffer $(\mathrm{pH} 7)$ and centrifuged for $30 \mathrm{~min}$ at $20,000 \times \mathrm{g}$ at $4^{\circ} \mathrm{C}$. An aliquot of the supernatant was then allowed to react with a solution of tetramethylbenzidine $(1.6 \mathrm{mM})$ and $0.1 \mathrm{mM}$ hydrogen peroxide. The rate of change in absorbance was measured spectrophotometrically at $450 \mathrm{~nm}$.

2.8. Measurement of TNF- $\alpha$ Levels. TNF- $\alpha$ levels were evaluated in the exudates $4 \mathrm{~h}$ after the induction of pleurisy by carrageenan injection. The assay was carried out by using an immunoenzymatic assay, commercial ELISA kit (ABCAM, CA, USA, cat. no. ab100747). The lower detection limit of the assay was $60 \mathrm{pg} / \mathrm{mL}$.

2.9. Measurement of NO. The Griess colorimetric reaction was used for the measurement of nitric oxide, involving the detection of nitrite $\left(\mathrm{NO}_{2}{ }^{-}\right)$and the oxidation of $\mathrm{NO}$ in the pleural fluid. In duplicate, $50 \mu \mathrm{L}$ of the pleural fluid was added to a 96-well ELISA plate, followed by the same volume of Griess reagent, which is composed of $1 \%$ sulfanilamide diluted in $2.5 \% \mathrm{H}_{3} \mathrm{PO}_{4}$ (solution $\mathrm{A}$ ) and $\mathrm{N}-1$-naphtylethylenediamine also diluted in $2.5 \% \mathrm{H}_{3} \mathrm{PO}_{4}$ (solution $\mathrm{B}$ ). To prepare the standard curve, a solution of sodium nitrite

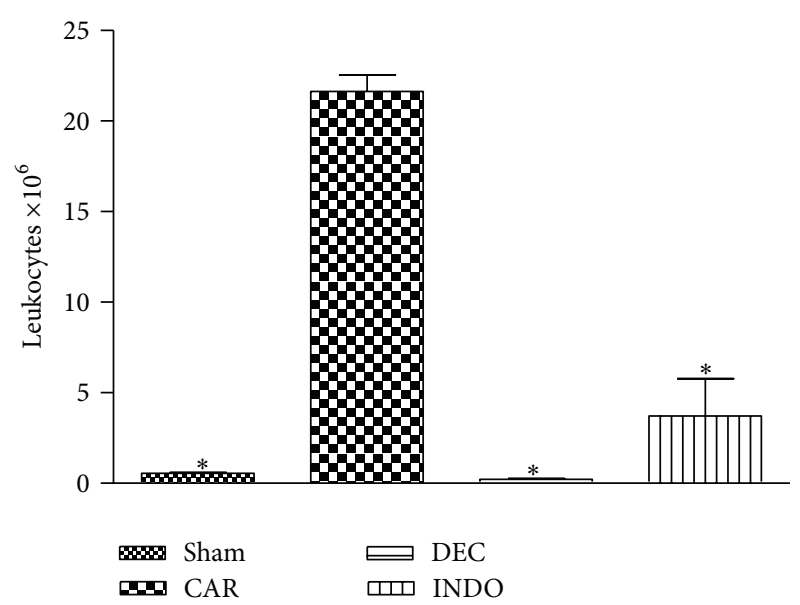

FIGURE 1: Effect of diethylcarbamazine (DEC: $50 \mathrm{mg} / \mathrm{Kg}$, three days before) on cell migration in the initial phase $(4 \mathrm{~h})$ of the inflammatory reaction induced by carrageenan in mice; data expressed as mean \pm S.E.M of 10 mice for each group; ${ }^{*} P<0.05$ versus carrageenan.

in an initial concentration of $100 \mu \mathrm{M}$ was serially diluted in PBS. After incubation for 10 minutes in the dark, reading was performed in the spectrophotometer at $490 \mathrm{~nm}$. The absorbance of different samples was compared with the standard curve and the results were expressed as mean \pm standard error of the duplicate, using the GraphPad Prism program (v. 5.0) [22].

2.10. Western Blot Analysis for $C O X-2, I L-1 \beta$, and NFKB. The lungs were quickly dissected and homogenized in a Wheaton Overhead Stirrer (no. 903475) in an extraction cocktail (10 $\mathrm{mM}$ ethylenediamine tetraacetic acid (EDTA), $2 \mathrm{mM}$ phenylmethylsulfonyl fluoride (PMSF), $100 \mathrm{mM}$ sodium fluoride $(\mathrm{NaF}), 10 \mathrm{mM}$ sodium pyrophosphate, $10 \mathrm{mM}$ sodium orthovanadate $\left(\mathrm{NaVO}_{4}\right), 10 \mathrm{mg}$ of aprotinin, and $100 \mathrm{mM}$ Tris(hydroxymethyl)aminomethane, $\mathrm{pH}$ 7.4). Homogenates were centrifuged at $3000 \times \mathrm{g}$ for $10 \mathrm{~min}$. The supernatant was stored at $-70^{\circ} \mathrm{C}$ until use for immunoblotting. Protein levels were determined by the Bradford method using bovine serum albumin as the standard [23]. The proteins $(40 \mu \mathrm{g} / \mu \mathrm{L})$ were separated on $10 \%$ (COX-2 and NF $\kappa$ B) or $14 \%(\mathrm{IL}-1 \beta)$ sodium dodecyl sulfate polyacrylamide by gel electrophoresis under reduced conditions and were electrophoretically transferred onto the nitrocellulose membrane (Bio Rad, CA, USA, Ref. 162-0115). After blocking overnight at $4^{\circ} \mathrm{C}$ with $5 \%$ nonfat milk in TBS-T (Tris-buffered saline $0.1 \%$ plus $0.05 \%$ Tween 20, pH 7.4), the membranes were incubated at room temperature for $3 \mathrm{~h}$ with rabbit polyclonal antibody against COX-2 (1:1,000 dilution; ABCAM, CA, USA), IL$1 \beta$ (1:2,000 dilution, Genway, San Diego, CA, USA) and $\mathrm{NF} \kappa \mathrm{B}$ (1: 200 dilution, Santa Cruz Biotechnology, Santa Cruz, CA, USA) diluted in buffer solution TBS-T containing 3\% nonfat milk. After washing six times (10 min each) in TBS$\mathrm{T}$, the membranes were further reacted with horseradish peroxidase-conjugated anti-rabbit or anti-mouse secondary antibody (1:80,000 (Ref. A6154) and 1:80,000 (Ref. A5420), 


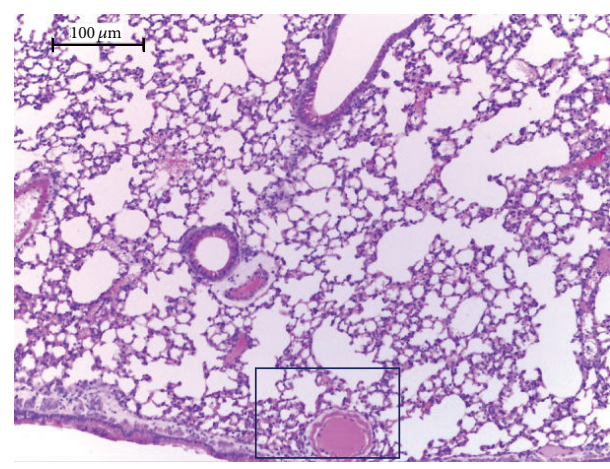

(A)

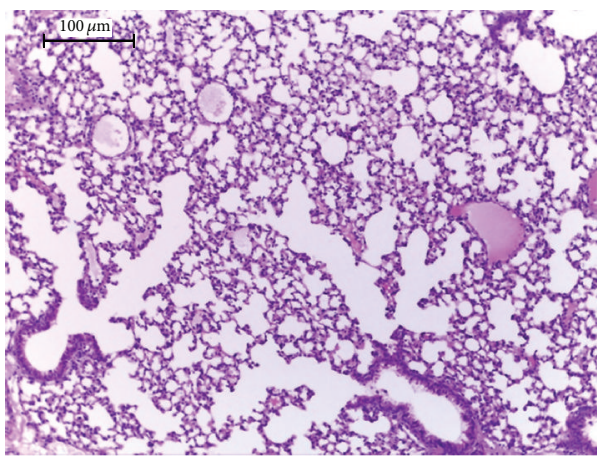

(B)

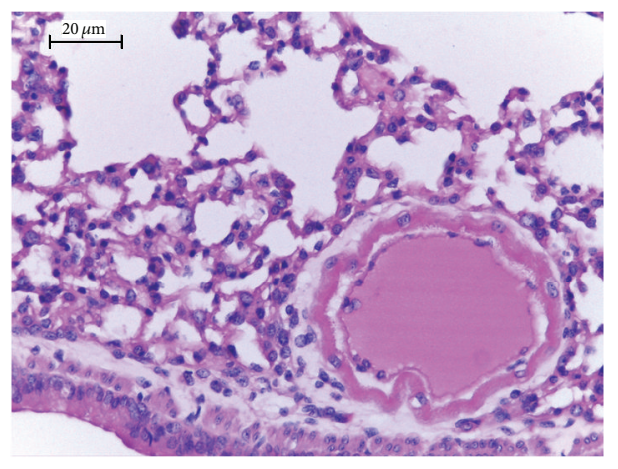

(A1)

(a)

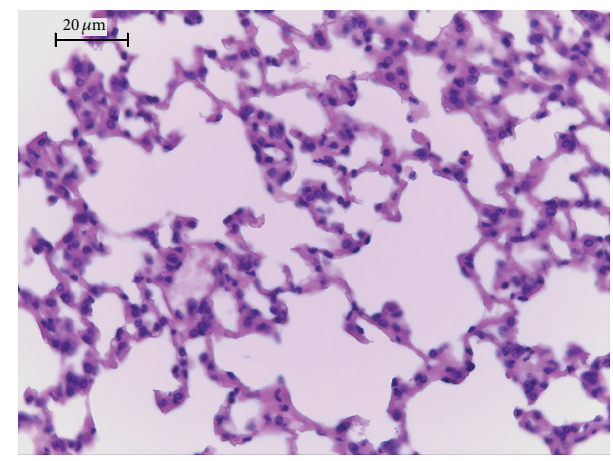

(B1)

(b)

FIGURE 2: Effect of DEC treatment on histological alterations in lung after carrageenan-induced injury; (A)-(A1) lung sections taken from mice with carrageenan-induced pleurisy demonstrated tissue injury as evidenced in edema, cellularity enhancement, and polymorphonuclear infiltration. (B)-(B1) Treatment with DEC three days prior to pleurisy demonstrated reduced lung injury and PMN infiltration. The figure is representative of at least 3 experiments performed on different experimental days. $n=10$ mice for each group; scale bar $=100 \mu \mathrm{m}$ and $20 \mu \mathrm{m}$.

respectively; Sigma, USA) diluted in TBS-T with $1 \%$ nonfat milk for $1 \mathrm{~h} 30 \mathrm{~min}$ at room temperature. An enhanced chemiluminescence reagent (Super Signal, Pierce, Ref. 34080) was used to make the labeled protein bands visible and the blots were developed on X-ray film (Fuji Medical, Kodak, Ref. Z358487-50EA). For quantification, the density of pixels of each band was determined using the Image 1.38 program (available at http://rsbweb.nih.gov/ij/download.html; developed by Wayne Rasband, NIH, Bethesda, MD, USA). For each protein investigated, the results were confirmed in three sets of experiments. Immunoblotting for $\beta$-actin was performed as a control for the above protein blots.

After the visualization of the protein blots with enhanced chemiluminescence, the protein antibodies were stripped from the membranes, which were reprobed with monoclonal anti- $\beta$-actin antibody (1:2,000 dilution, Sigma, USA), and protein densitometry was subsequently performed.

2.11. Data Analysis. All values are expressed as mean and standard error of the mean ( \pm S.E.M.) of $n$ observations. In the in vivo studies, $n$ represents the number of animals studied. The results were analyzed by one-way ANOVA followed by
Tukey's posttest, using the GraphPad Prism program (V. 5.0). All $P$ values less than 0.05 were considered significant.

\section{Results}

3.1. Effect of DEC on Leukocyte Migration. The injection of carrageenan into the pleural cavity of mice induced an acute inflammatory response characterized by the accumulation of fluid containing a large amount of PMNs. However, the number of PMNs was significantly reduced with prior treatment for three days with DEC and INDO $(0.22 \pm 0.09 \times$ $10^{6}$ and $3.72 \pm 5.05 \times 10^{6}$ leukocytes, resp.) compared to the group that received carrageenan without prior treatment $\left(21.63 \pm 2.27 \times 10^{6}\right.$ leukocytes) (Figure 1$)$.

\subsection{Effect of Diethylcarbamazine on Carrageenan-Induced} Tissue Damage. The histological analysis revealed that the animals with carrageenan-induced pleurisy exhibited discrete alveolar thickening due to increased cellularity, mild hemorrhage and congestion, apoptotic cells, inflammatory cells (mononuclear and polymorphonuclear cells), and pulmonary edema and emphysema (Figure 2(a)). Treatment for three days with DEC attenuated the degree of injury and 


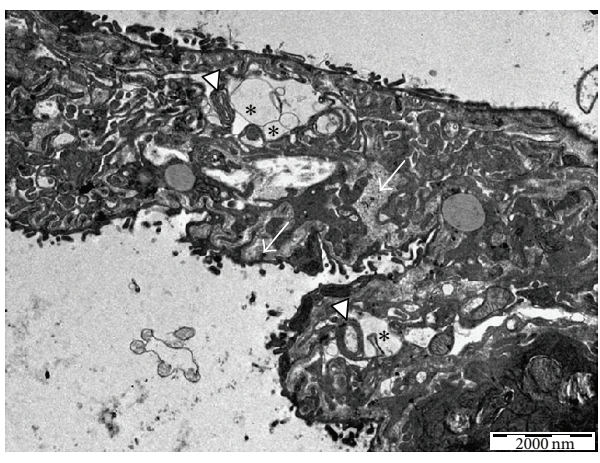

(a)

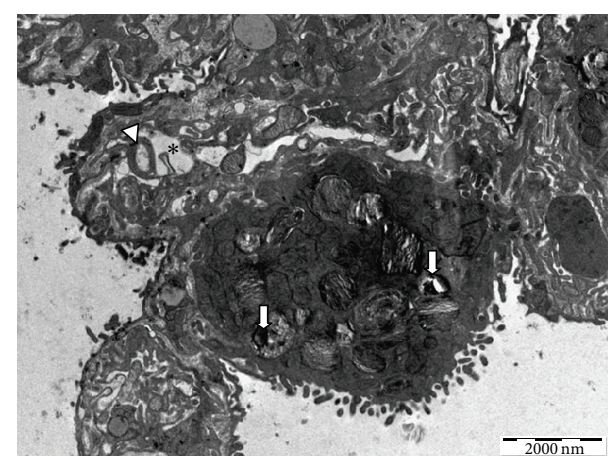

(b)

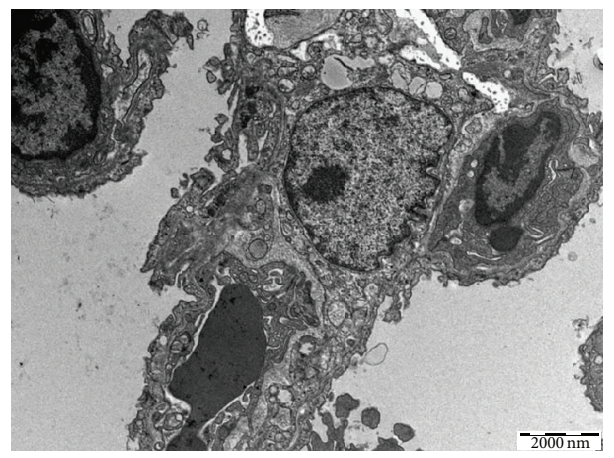

(c)

FIGURE 3: Ultrastructural analysis of lung after carrageenan-induced injury and DEC treatment; (a) and (b) lung sections from mice with carrageenan-induced pleurisy showing enhanced thickness of the interstitial space filled with collagen fibers (thin arrows), myelin bodies (arrowheads), vacuoles (asterisks), and lamellar bodies containing electrodense granules (short arrows); (c) lung treated with DEC presenting preserved pneumocytes; $b a r=2000 \mathrm{~nm}$.

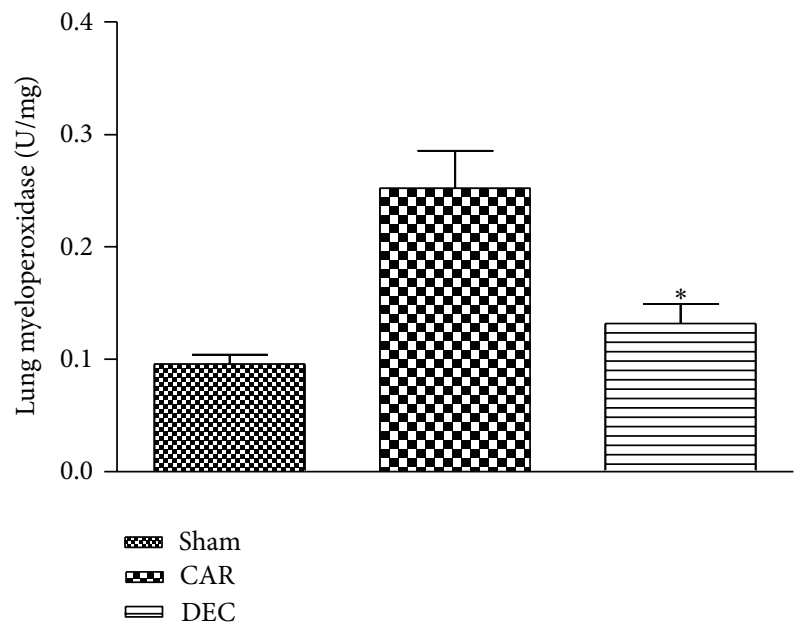

FIGURE 4: Within $4 \mathrm{~h}$, pleural injection of carrageenan led to an increase in neutrophil accumulation in the lung. DEC treatment significantly inhibited neutrophil infiltration. Data expressed as mean \pm S.E.M. from $n=8$ mice for each group; ${ }^{*} P<0.05$ versus carrageenan.

the infiltration of PMNs (Figure 2(b)). The lungs in the sham group exhibited preserved morphological characteristics.
The pulmonary ultrastructural analysis of the animals in the sham group revealed a preserved morphological pattern, such as respiratory spaces, including the alveolar epithelium composed of pneumocytes (not shown). The lung tissue of animals with carrageenan-induced pleurisy revealed type II pneumocytes with lamellar bodies containing electrodense granules, vacuoles, and myelin bodies, characterizing cell suffering. Numerous collagen fibers were also observed in the interstitial space, increasing its thickness (Figures 3(a) and 3(b)). The animals treated with DEC exhibited a preserved alveolar epithelium similar to that found in the sham group (Figure 3(c)).

3.3. Effect of DEC on MPO Activity in Mice. The pleural infiltration with PMN appeared to correlate with an influx of leukocytes into the lung tissue; thus we investigated the effect of DEC on neutrophil infiltration by measurement of MPO activity. This enzyme activity was significantly elevated at $4 \mathrm{~h}$ after CAR administration. Treatment with DEC significantly attenuated a neutrophil infiltration into the lung tissue (Figure 4).

3.4. Effect of DEC on Expression of TNF- $\alpha$, IL-1 $\beta, C O X-2$, and $i N O S$. The expression of TNF- $\alpha$, IL- $1 \beta$, COX-2, and iNOS in the lung tissue was evaluated by immunohistochemical 


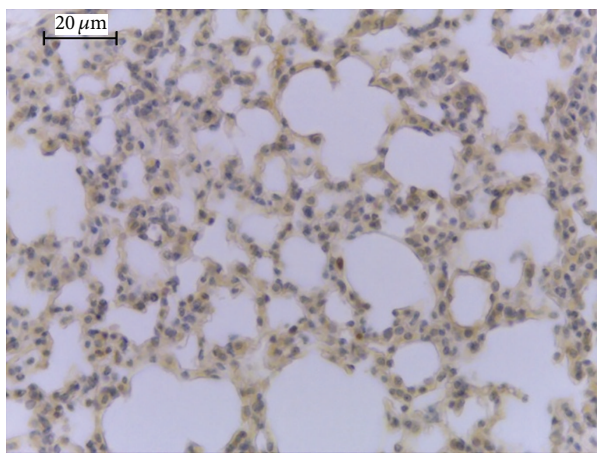

(a)

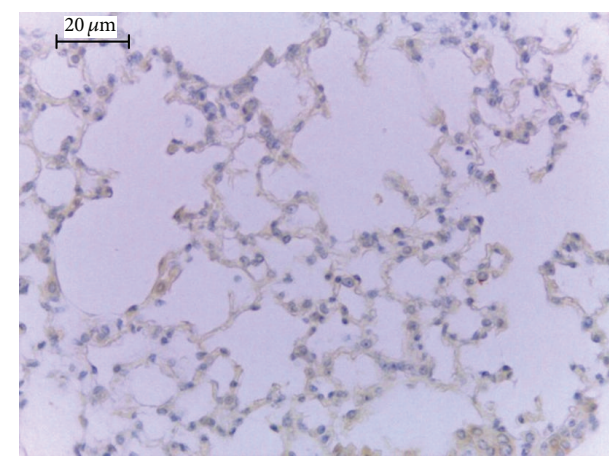

(b)

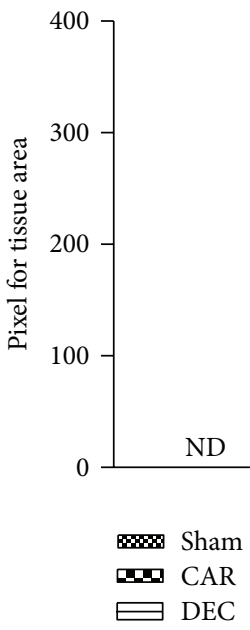

(c)

FIGURE 5: Effect of DEC on immunohistochemical localization TNF- $\alpha$ in lung after carrageenan-induced pleurisy. (a) In tissue sections obtained from the CAR group, positive staining for TNF- $\alpha$ was mainly located in inflammatory cells. (b) After treatment with DEC, the degree of positive staining for TNF- $\alpha$ was reduced in the lung tissue. (c) Densitometry analysis of immunohistochemistry photographs for TNF- $\alpha$ in lung tissues; figure representative of at least 3 experiments performed on different experimental days; data expressed as mean \pm S.E.M. from $n=5$ mice for each group; ND: not detected; ${ }^{*} P<0.05$ versus carrageenan; scale bar $=20 \mu \mathrm{m}$.

detection. Tissue sections obtained from mice in the CAR group had positive staining for TNF- $\alpha$ in the alveolar cells, macrophages, and vascular wall (Figure 5(a); densitometry analysis: Figure 5(c)). In contrast, no staining for TNF- $\alpha$ was found in the lungs of mice treated with DEC (Figure 5(b); densitometry analysis: Figure 5(c)). Likewise, no positive staining for TNF- $\alpha$ was found in lung tissue from the shamtreated mice.

Lung tissue sections from mice in the CAR group demonstrated a positive reaction for IL- $1 \beta$ in alveolar macrophages (Figure 6(a); densitometry analysis: Figure 6(c)). Treatment with DEC for three days significantly reduced the degree of IL-1 $\beta$ expression (Figure 6(b); densitometry analysis: Figure $6(\mathrm{c})$ ). There was no labeling for IL-1 $\beta$ in lung tissue obtained from mice in the sham group.

The lung tissue sections obtained from mice in the CAR group revealed considerable COX-2 expression (Figure 7(a); densitometry analysis Figure 7(c)), whereas COX-2 expression was significantly reduced in lung sections obtained from mice treated with DEC (Figure 7(b); densitometry analysis:
Figure $7(\mathrm{c})$ ). Lung sections from the mice in the sham group expressed baseline levels of COX-2.

Lung sections obtained from mice in the CAR group revealed positive staining for iNOS in alveolar macrophages (Figure 8(a); densitometry analysis: Figure 8(c)), whereas DEC treatment significantly attenuated iNOS expression (Figure 8(b); densitometry analysis: $8 \mathrm{C}$ ). Little staining for iNOS was observed in the lung tissue obtained from the sham group.

\subsection{Effect of DEC on TNF- $\alpha$ and NO Concentration in Pleural} Exudate. The concentration of TNF- $\alpha$ in the pleural exudate was analyzed using enzyme-linked immunosorbent assays (ELISA). Carrageenan-induced pleurisy promoted high levels of TNF- $\alpha$ in the pleural exudate in comparison to the sham group, whereas treatment with DEC for three days prior to the induction of pleurisy significantly attenuated the production of TNF- $\alpha$. In contrast, treatment with indomethacin promoted no reduction in the level of this proinflammatory cytokine (Figure 9(a)). 


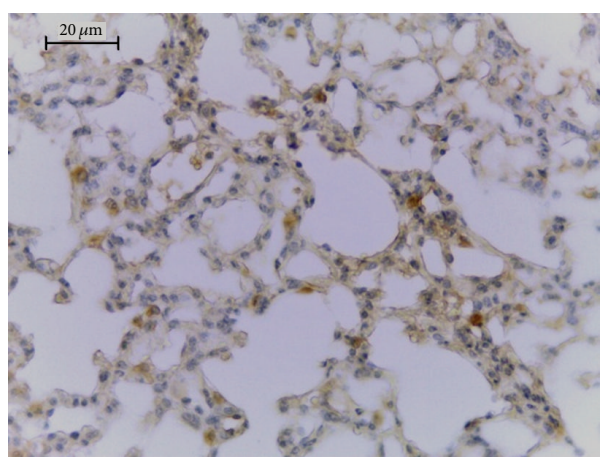

(a)

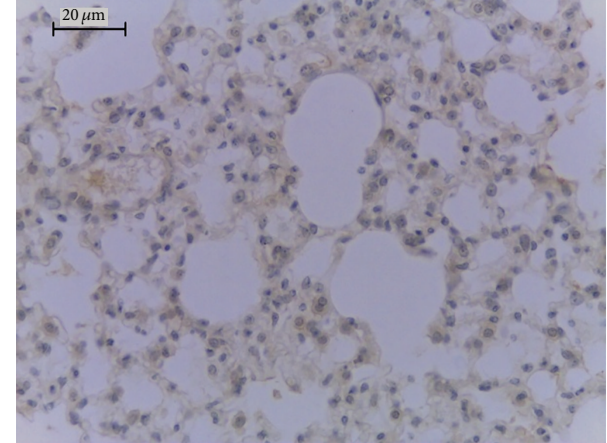

(b)

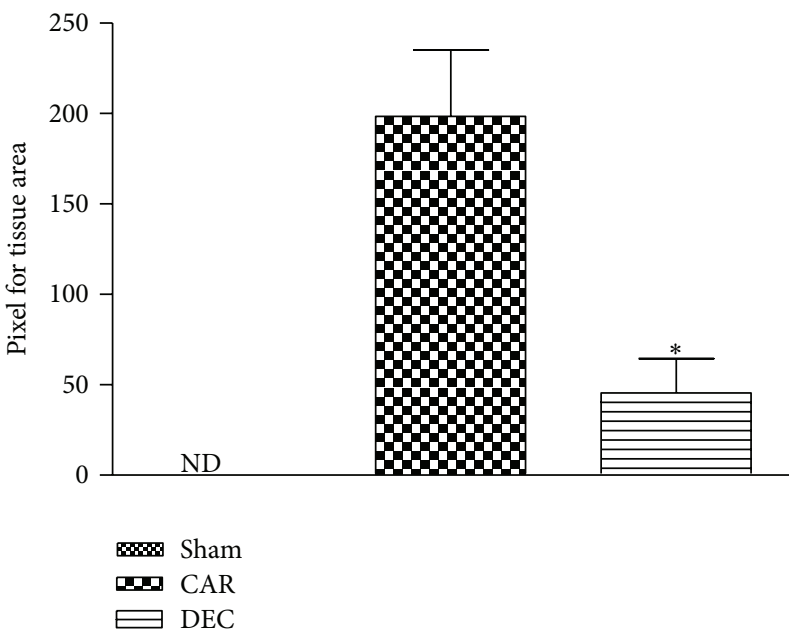

(c)

Figure 6: Effects of DEC on immunohistochemical localization of IL-1 $\beta$. (a) At $4 \mathrm{~h}$ after carrageenan injection, staining intensity for IL-1 $\beta$ substantially increased in alveolar macrophages. (b) No positive staining for IL-1 was found when DEC was administered three days prior to carrageenan injection. (c) Densitometry analysis of immunohistochemistry photographs for IL-1- $\beta$ in lung tissues; figure representative of at least 3 experiments performed on different experimental days; data expressed as mean \pm S.E.M. from $n=5$ mice for each group; ND: not detected; ${ }^{*} P<0.05$ versus carrageenan; scale bar $=20 \mu \mathrm{m}$.

$\mathrm{NO}$ in the pleural exudate were analyzed through the Griess reaction. NO levels increased significantly in the exudate in the CAR group in comparison to the sham group. However, treatment with DEC and INDO significantly reduced $\mathrm{NO}$ levels in comparison to the CAR group (Figure 9(b)).

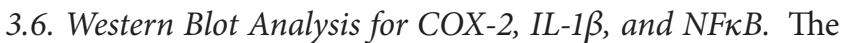
presence of COX-2 in the lung homogenate was investigated by western blot analysis 4 hours after the induction of pleurisy. Baseline levels of COX-2 were detected in the mice in the sham group, whereas COX-2 levels were significantly increased in lung tissue from the CAR group. However, treatment with DEC significantly reduced the expression of COX-2. Unexpectedly, treatment with indomethacin did not reduce the levels of COX-2 in comparison to the CAR group (Figure 10).

Baseline levels of IL- $1 \beta$ expression were detected in the lung homogenate from the sham group, whereas increased levels were found in the CAR group. Treatment with DEC and
INDO decreased significantly the IL- $1 \beta$ levels in comparison to the CAR group (Figure 11).

$\mathrm{NF} \kappa \mathrm{B}$ p65 levels in the lung were also significantly increased at $4 \mathrm{~h}$ after carrageenan injection in comparison to the sham group, whereas DEC and INDO both significantly decreased the $\mathrm{NF} \kappa \mathrm{B}$ levels in comparison to the CAR group (Figure 12).

\section{Discussion}

Acute pulmonary inflammation is associated with the enhanced formation of the proinflammatory cytokines TNF$\alpha$ and IL- $1 \beta$, inducible COX-2, and the production of reactive oxygen species (ROS), such as hydrogen peroxide, superoxide, and hydroxyl radicals $[9,24]$. In the present study, the injection of carrageenan into the pleural cavity induced PMNs infiltration, lung injury (characterized by cellular infiltration, edema, alveolar thickness, myelin bodies, and large vacuoles), and the production of proinflammatory cytokines as well as COX-2 and NOS. Moreover, the histological and 


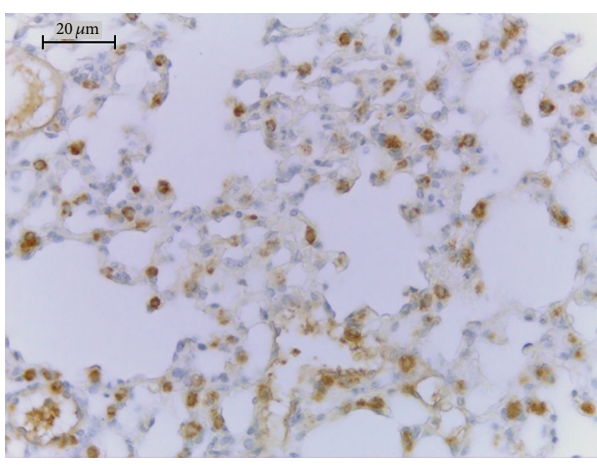

(a)

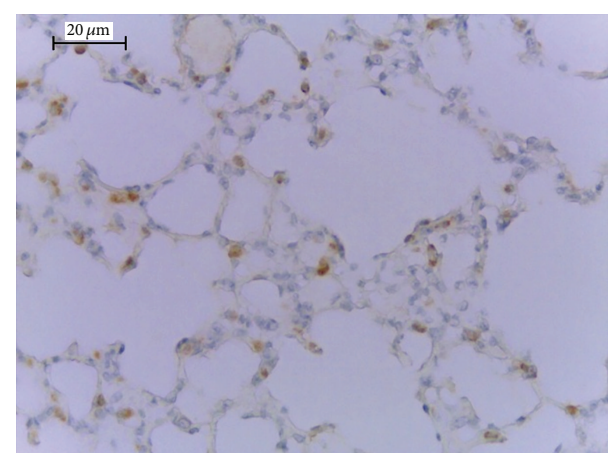

(b)

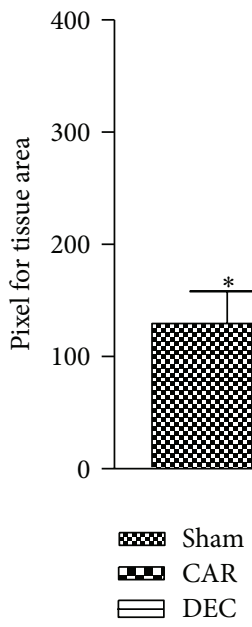

(c)

FIGURE 7: Effect of DEC on immunohistochemical localization of COX-2 in lung tissue after pleurisy induced by carrageenan. (a) In tissue sections from the CAR group, positive labeling was detected on type II pneumocytes. (b) Treatment with DEC significantly reduced COX-2 staining in comparison to the CAR group, achieving levels similar to the sham group. (c) Densitometry analysis of immunohistochemistry photographs for COX-2 from lung tissues; figure is representative of at least 3 experiments performed on different experimental days; data expressed as mean \pm S.E.M. from $n=5$ mice for each group; ND: not detected; ${ }^{*} P<0.05$ versus carrageenan; scale bar $=20 \mu \mathrm{m}$.

ultrastructural analyses demonstrated that DEC efficiently blocked carrageenan-induced lung injury.

Oxidative stress has been shown to play a critical role in acute and chronic inflammatory responses, such as lung injury. The activation of leukocytes, such as neutrophils, prior to the cell responses involved in the acute inflammatory process promotes the release of several types of ROS [17]. NO synthesized by iNOS is another free radical present during inflammation and capable of interacting with ROS to increase the action of free radicals [25]. These radicals are released by various cell types in response to stimulation by TNF- $\alpha$ and IL-1 $\beta$, all of which activate a cytoplasmic form of the transcription factor NF-kappaB by releasing an inhibitory protein subunit [26].

Experimental evidence has clearly suggested that NF- $\kappa \mathrm{B}$ plays a central role in the regulation of a large number of genes responsible for the generation of mediators or proteins in carrageenan-induced acute lung inflammation, such as TNF- $\alpha$, IL- $1 \beta$, iNOS, and COX-2 [8]. The present findings demonstrate that the inflammatory process caused by the injection of carrageenan into the pleural cavity leads to a substantial increase in levels of TNF- $\alpha$ and IL-1 $\beta$ in the exudate and lung tissue. Therefore, the inhibition of the release of TNF- $\alpha$ and IL-1 $\beta$ by DEC described in the present study could be attributed to the inhibitory effects of the activation of NF- $\kappa$ B. However, further studies are needed to clarify the signal transduction pathways involved.

In human lungs, neutrophils, eosinophils, macrophages, platelets, and airway epithelial cells have been described as the main cellular sources of lipoxygenase-derived arachidonic acid products and DEC has been used as a potent lipoxygenase inhibitor of alveolar macrophages by blocking the release of chemotactic activity [27]. Moreover, Stenmark et al. [28] found that DEC blocks the lipoxygenase pathway in the pathogenesis of pulmonary hypertension induced by monocrotaline in mice. Lipoxygenase products are potent inflammatory agents that induce vascular permeability and bronchoconstriction. According to the authors cited, treatment with DEC improved systolic blood pressure and heart weight, reduced the number of PMNs in the bronchoalveolar lavage fluid, and decreased levels of prostaglandins and thromboxane. 


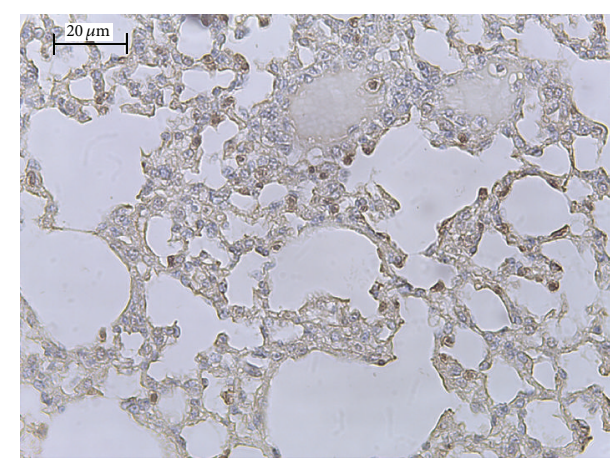

(a)

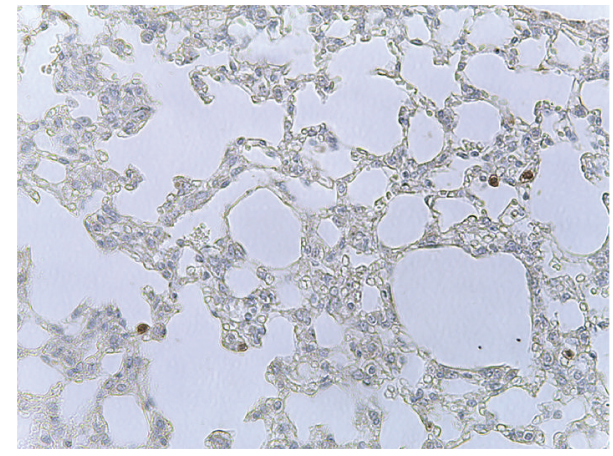

(b)

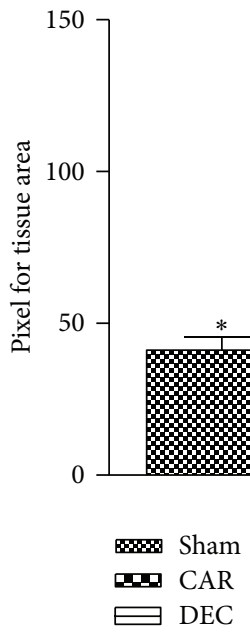

(c)

FIGURE 8: Effect of DEC on immunohistochemical localization of iNOS in lung tissue after pleurisy induced by carrageenan. (a) In tissue sections from the CAR group, positive labeling was detected on alveolar macrophages. (b) Treatment with DEC significantly reduced the iNOS staining in comparison to the CAR group, achieving levels similar to the sham group. (c) Densitometry analysis of immunohistochemistry photographs for iNOS from lung tissues; figure representative of at least 3 experiments performed on different experimental days; data expressed as mean \pm S.E.M. from $n=5$ mice for each group; ${ }^{*} P<0.05$ versus carrageenan; scale bar $=20 \mu \mathrm{m}$.

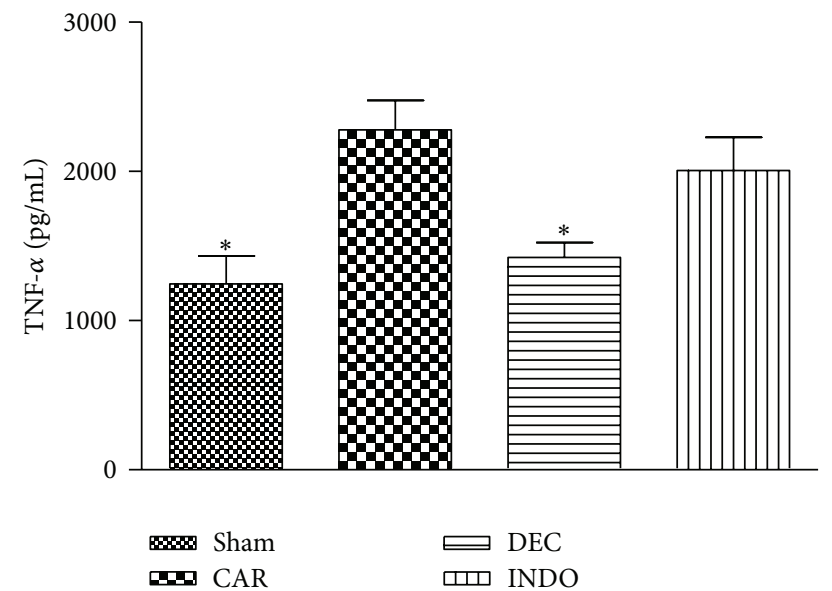

(a)

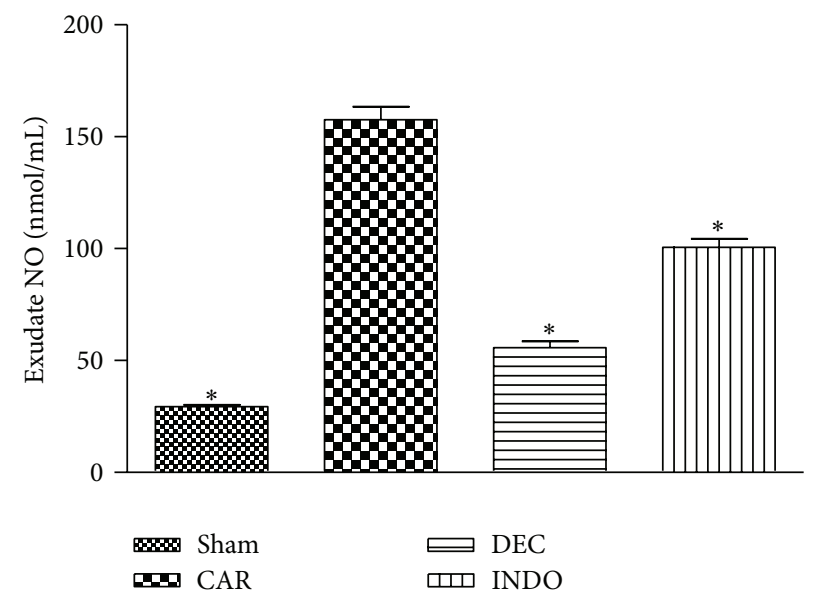

(b)

FIGURE 9: Effect of DEC on carrageenan-induced TNF- $\alpha$ and NO production in the lung. (a) TNF- $\alpha$ levels were significantly elevated $4 \mathrm{~h}$ after carrageenan administration in the CAR group in comparison to the sham group. DEC significantly reduced the TNF- $\alpha$ level, but INDO did not reduce TNF- $\alpha$ level in comparison to the CAR group. Nitrite and nitrate levels, stable NO metabolites, were significantly increased in the pleural exudates $4 \mathrm{~h}$ after carrageenan administration in comparison to the sham group. DEC and INDO significantly reduced the nitrite and nitrate level in the exudates (b). Data expressed as mean \pm S.E.M. from $n=8$ mice for each group; ${ }^{*} P<0.05$ versus carrageenan. 


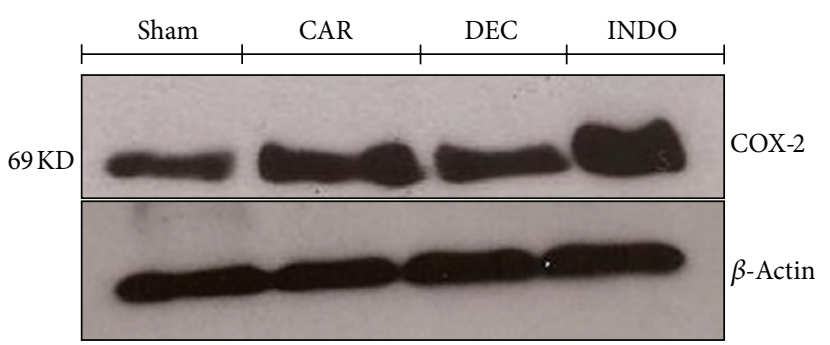

(a)

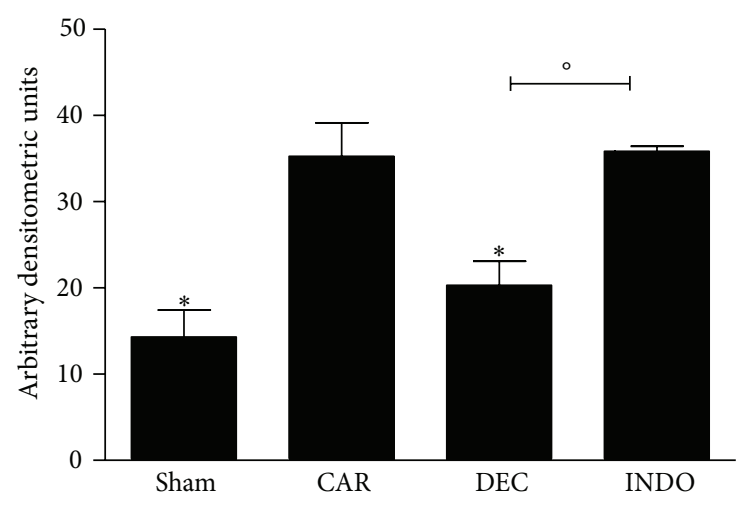

(b)

FIGURE 10: Effects of DEC on carrageenan-induced COX-2 expression in the lung. Basal expression of COX-2 was detected in lung samples from the sham group, whereas COX-2 levels were substantially elevated in lung tissue obtained from animals $4 \mathrm{~h}$ after carrageenan injection. DEC treatment reduced the expression of COX-2, but treatment with indomethacin did not decrease the levels of COX-2 (a) and (b). (a) Representative blot of lysates obtained from pool 4 animals per group; (b) data expressed as mean \pm S.E.M. of 4 replications for each group; ${ }^{*} P<0.05$ versus carrageenan; ${ }^{\circ} P<0.05$ versus DEC.

Carrageenan-induced pleurisy is a well-characterized experimental model of inflammation used to evaluate cell migration and other inflammatory parameters. Nonsteroidal anti-inflammatory drugs are effective in inhibiting both cell migration and exudation [29]. Based on the present results, the injection of carrageenan into the pleural cavity induced PMNs infiltration, but treatment with DEC significantly reduced the number of leucocytes in the exudate.

Using a carrageenan-induced model of acute inflammation, Tomlinson et al. [9] demonstrated that the influx of PMNs increases the production of COX-2 and iNOS following the induction of pleurisy, as the inflammation progressed and the cell population changed from the PMN to mononuclear profile and there was a decrease in COX and NOS activity. The authors suggest that the use of selective inhibitors of COX-2 and iNOS in acute inflammation may be more beneficial than existing therapies. In general, iNOSderived NO and COX-2-derived PGs are involved in both acute and chronic inflammation [30].

There is ample evidence in carrageenan and other models of inflammation that the enhanced formation of prostanoids

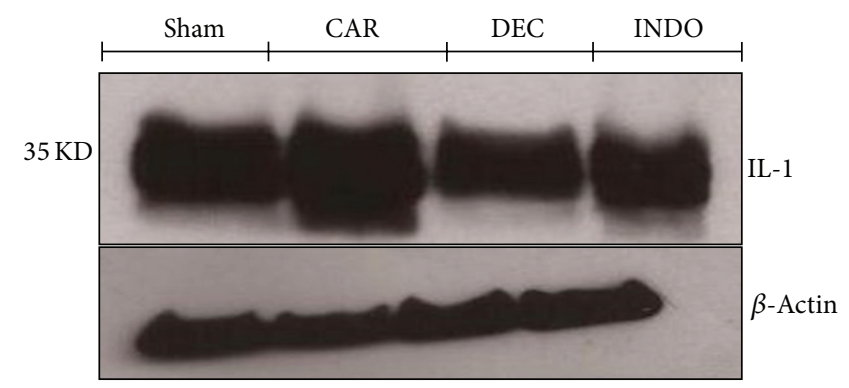

(a)

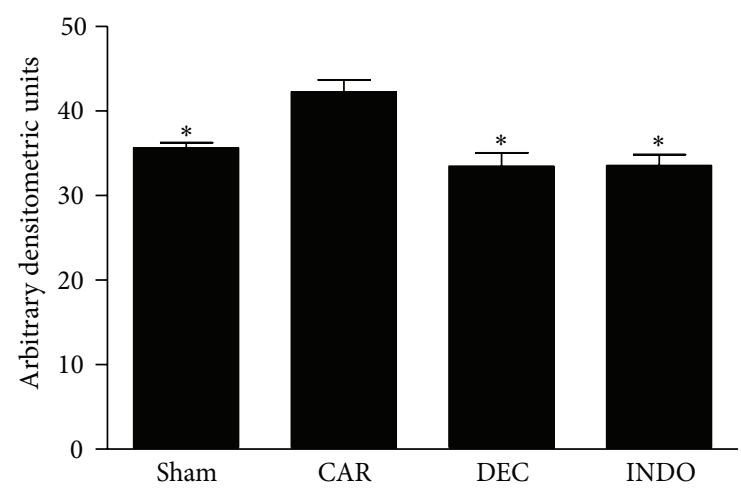

(b)

FIGURE 11: Effects of DEC on carrageenan-induced IL-1 $\beta$ expression in the lung. Basal expression of IL- $1 \beta$ was detected in lung samples obtained from the sham group, whereas levels of IL- $1 \beta$ were significantly increased in the lung tissue from animals 4 hours after injection of carrageenan. Treatment with DEC and INDO reduced the expression of IL- $1 \beta$ in comparison to the CAR group. (a) Representative blot of lysates obtained from pool 4 animals per group; (b) data expressed as mean \pm S.E.M. of 3 replications for each group; ${ }^{*} P<0.05$ versus carrageenan.

following the induction of COX-2 contributes to the pathophysiology of local inflammation $[31,32]$ and that selective inhibitors of COX-2 exert potent anti-inflammatory effects. The present results demonstrate that treatment with DEC significantly decreased the levels of COX-2 in lung tissue, as observed with other nonsteroidal anti-inflammatory drugs. DEC inhibits platelet aggregation, possibly due to its effects on the COX pathway [2], which has similarities with the NO pathway, since both have constitutive and inducible isoforms of their enzymes and are key regulators of inflammatory responses $[33,34]$.

In a study with knockout mice for the iNOS gene (iNOS -/-), Mcgarry et al. [35] demonstrated that nitric oxide synthase (iNOS) pathways likely exert an effect on DEC activity through the interaction with the cyclooxygenase. The authors found that DEC had no microfilaricidal activity in iNOS-deficient mice infected with $B$. malayi and there was a remarkable reduction in the COX-1 protein in the peritoneal exudate. Therefore, the iNOS/COX pathway appears to be an essential event in the rapid sequestration of microfilariae following treatment with DEC. 


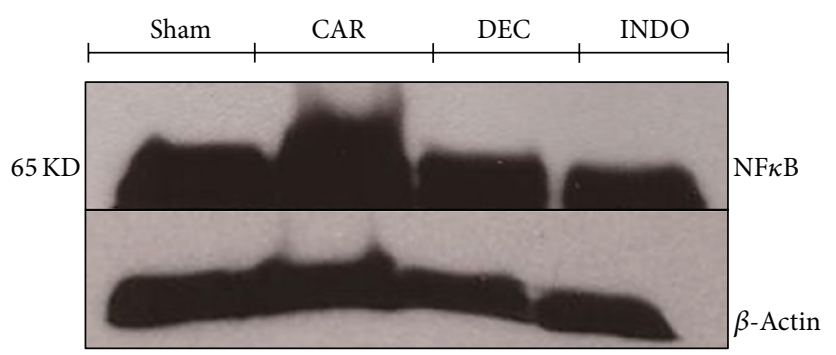

(a)

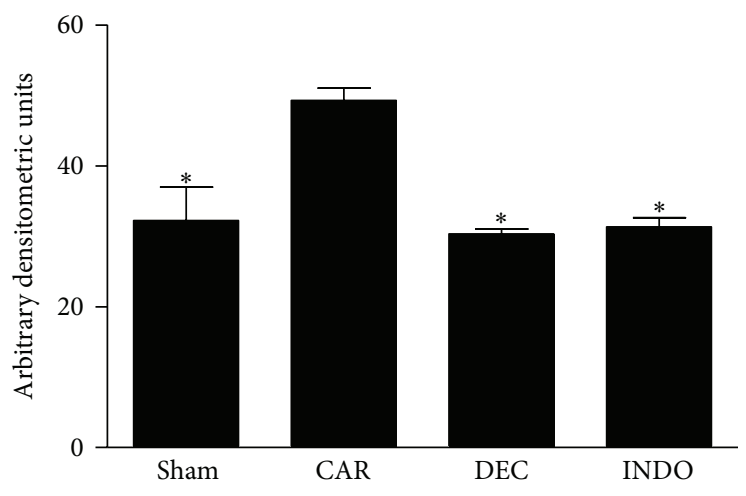

(b)

FIGURE 12: Effects of DEC on carrageenan-induced NF $\kappa$ B expression in the lung. Basal expression of $\mathrm{NF} \kappa \mathrm{B}$ was detected in lung samples obtained from the sham group, whereas $\mathrm{NF} \kappa \mathrm{B}$ levels were significantly increased in lung tissue of animals 4 hours after injection of carrageenan. Treatment with DEC and INDO reduced NFKB expression in comparison to the CAR group. (a) Representative blot of lysates obtained from pool 4 animals per group; (b) data expressed as mean \pm S.E.M. of 3 replications for each group; ${ }^{*} P<0.05$ versus carrageenan.

Queto et al. [7] demonstrated that DEC has an important action in blocking eosinophilic lung inflammation in mice sensitized with ovalbumin. Treatment with DEC reduced the amount of eosinophils in bronchoalveolar fluid and tissue infiltrate and altered the generation of cytokines involved in the production, activation, and migration of eosinophils. The authors provide the first evidence of the therapeutic mechanism of DEC in a model eosinophilic lung inflammation. Interestingly, DEC blocks pulmonary hyperreactivity, Th2 cytokine production, and the accumulation of eosinophils as well as eosinophilopoiesis both in vivo and in vitro through iNOS/CD95L mechanisms.

Inhibitors of NOS activity reduce the development of carrageenan-induced inflammation and indicate a role for NO in the pathophysiology associated with this inflammation model $[36,37]$. The present results demonstrate the inhibition of NOS activity following treatment with DEC, since the formation of nitrite was evidently reduced in the pleural exudates.

In conclusion, the present findings demonstrate for the first time that the administration of DEC in a model of acute inflammation induced by carrageenan led to reductions in lung injury, PMNs migration, the formation of $\mathrm{NO}$ production, and the release of proinflammatory cytokines and COX-2, thereby confirming previous observations that DEC effectively acts through the NOS/COX mechanism.

\section{Conflict of Interests}

The authors declare that there is no conflict of interests regarding the publication of this paper.

\section{Acknowledgments}

This study was supported by the Fundação de Amparo à Ciência e Tecnologia do Estado de Pernambuco (FACEPE), Aggeu Magalhães Research Center of the Oswaldo Cruz Foundation in Recife, Brazil (CPqAM/FIOCRUZ), and National Institute of Structural Biology and Bioimagem (INBEB).

\section{References}

[1] R. I. S. Hewitt, H. W. Kushner, E. Stewart, W. S. White, and Y. Wallace, "Experimental chemotherapy of filariasis. III. Effect of 1-diethylcarbamyl-4-methylpiperazine hydrochloride against naturally acquired filarial infections in cotton rats and dogs," Journal of Laboratory and Clinical Medicine, vol. 32, pp. 13141329, 1947.

[2] R. M. Maizels and D. A. Denham, "Diethylcarbamazine (DEC): immunopharmacological interactions of an anti-filarial drug," Parasitology, vol. 105, pp. 849-860, 1992.

[3] W. R. Mathews and R. C. Murphy, "Inhibition of leukotriene biosynthesis in mastocytoma cells by diethylcarbamazine," Biochemical Pharmacology, vol. 31, no. 11, pp. 2129-2132, 1982.

[4] M. K. Bach and J. R. Brashler, "Inhibition of the leukotriene synthetase of rat basophil leukemia cells by diethylcarbamazine, and synergism between diethylcarbamazine and piriprost, a 5lipoxygenase inhibitor," Biochemical Pharmacology, vol. 35, no. 3, pp. 425-433, 1986.

[5] H. V. Srinivas and J. Antani, "Diethylcarbamazine in bronchial asthma," Annals of Allergy, vol. 29, no. 8, pp. 418-421, 1971.

[6] K. V. Thiruvengadam, N. Subramanian, T. V. Devarajan, and M. G. M. Zachariah, "Diethylcarbamazine citrate in bronchial asthma," Journal of the Indian Medical Association, vol. 63, no. 9, pp. 278-281, 1974.

[7] T. Queto, P. Xavier-Elsas, M. A. Gardel et al., "Inducible nitric oxide synthase/CD95L-dependent suppression of pulmonary and bone marrow eosinophilia by diethylcarbamazine," American Journal of Respiratory and Critical Care Medicine, vol. 181, no. 5, pp. 429-437, 2010.

[8] D. Impellizzeri, E. Esposito, E. Mazzon et al., "Effect of apocynin, a NADPH oxidase inhibitor, on acute lung inflammation," Biochemical Pharmacology, vol. 81, no. 5, pp. 636-648, 2011.

[9] A. Tomlinson, I. Appleton, A. R. Moore et al., "Cyclo-oxygenase and nitric oxide synthase isoforms in rat carrageenin-induced pleurisy," British Journal of Pharmacology, vol. 113, no. 3, pp. 693-698, 1994

[10] J. Vane and R. Botting, "Inflammation and the mechanism of action of anti-inflammatory drugs," The FASEB Journal, vol. 1, no. 2, pp. 89-96, 1987.

[11] E. M. Dalmarco, Y. S. Medeiros, and T. S. Fröde, "Cyclosporin A inhibits CD11a/CD18 adhesion molecules due to inhibition of 
TNFalpha and IL-1 beta levels in the mouse model of pleurisy induced by carrageenan," Cell Adhesion \& Migration, vol. 2, no. 4, pp. 231-235, 2008.

[12] K. P. Barbosa, L. A. Santos, E. L. Ribeiro et al., "Reduction of carrageenan-induced acute pulmonary inflammation in mice by novel thiazolidinedione derivative LPSF/RA-4," European Journal of Pharmacology, vol. 718, no. 1-3, pp. 197-205, 2013.

[13] C. Crisafulli, E. Mazzon, I. Paterniti, M. Galuppo, P. Bramanti, and S. Cuzzocrea, "Effects of liver $\mathrm{x}$ receptor agonist treatment on signal transduction pathways in acute lung inflammation," Respiratory Research, vol. 11, article 19, 2010.

[14] F. Nantel, D. Denis, R. Gordon et al., "Distribution and regulation of cyclooxygenase-2 in carrageenan-induced inflammation," British Journal of Pharmacology, vol. 128, no. 4, pp. 853859, 1999.

[15] World Health Organization, "Global programme to eliminate lymphatic filariasis," Annual Report on Lymphatic Filariases 113, Geneva, Switzerland, 2002.

[16] A. H. M. Terpstra, "Differences between humans and mice in efficacy of the body fat lowering effect of conjugated linoleic acid: role of metabolic rate," Journal of Nutrition, vol. 131, no. 7, pp. 2067-2068, 2001.

[17] E. M. Dalmarco, P. Budni, E. B. Parisotto, D. W. Filho, and T. S. Frode, "Antioxidant effects of mycophenolate mofetil in a murine pleurisy model," Transplant Immunology, vol. 22, no. 1-2, pp. 12-17, 2009.

[18] M. Menegazzi, R. di Paola, E. Mazzon et al., "Glycyrrhizin attenuates the development of carrageenan-induced lung injury in mice," Pharmacological Research, vol. 58, no. 1, pp. 22-31, 2008.

[19] K. L. A. Saraiva, V. A. Silva Jr., E. S. F. Dias, and C. A. Peixoto, "Morphological changes in the testis induced by diethylcarbamazine," Reproductive Toxicology, vol. 22, no. 4, pp. 754-759, 2006.

[20] K. L. A. Saraiva, A. K. S. Silva, M. I. Wanderley, A. A. Araújo, J. R. B. Souza, and C. A. Peixoto, "Chronic treatment with sildenafil stimulates Leydig cell and testosterone secretion," International Journal of Experimental Pathology, vol. 90, no. 4, pp. 454-462, 2009.

[21] K. M. Mullane, R. Kraemer, and B. Smith, "Myeloperoxidase activity as a quantitative assessment of neutrophil infiltration into ischemic myocardium," Journal of Pharmacological Methods, vol. 14, no. 3, pp. 157-167, 1985.

[22] I. Guevara, J. Iwanejko, A. Dembińska-Kieć et al., "Determination of nitrite/nitrate in human biological material by the simple Griess reaction," Clinica Chimica Acta, vol. 274, no. 2, pp. 177188, 1998.

[23] M. A. Bradford, "A rapid and sensitive method for the quantitation of microgram quantities of protein utilizing the principle of protein-dye binding," Analytical Biochemistry, vol. 72, no. 1-2, pp. 240-254, 1970.

[24] S. Cuzzocrea, L. Sautebin, G. de Sarro et al., "Role of IL-6 in the pleurisy and lung injury caused by carageenan," Journal of Immunology, vol. 163, no. 9, pp. 5094-5104, 1999.

[25] S. Cuzzocrea, E. Mazzon, G. Calabro et al., "Inducible nitric oxide synthase-knockout mice exhibit resistance to pleurisy and lung injury caused by carrageenan," American Journal of Respiratory and Critical Care Medicine, vol. 162, no. 5, pp. 1859$1866,2000$.

[26] E. Talero, R. di Paola, E. Mazzon, E. Esposito, V. Motilva, and S. Cuzzocrea, "Anti-inflammatory effects of adrenomedullin on acute lung injury induced by Carrageenan in mice," Mediators of Inflammation, vol. 2012, Article ID 717851, 13 pages, 2012.

[27] H. Nomura, E. Sato, S. Koyama et al., "Histamine stimulates alveolar macrophages to release neutrophil and monocyte chemotactic activity," Journal of Laboratory and Clinical Medicine, vol. 138, no. 4, pp. 226-235, 2001.

[28] K. R. Stenmark, M. L. Morganroth, L. K. Remigio et al., "Alveolar inflammation and arachidonate metabolism in monocrotaline-induced pulmonary hypertension," The American journal of physiology, vol. 248, no. 6, part 2, pp. H859-H866, 1985.

[29] T. S. F. Saleh, J. B. Calixto, and Y. S. Medeiros, "Effects of antiinflammatory drugs upon nitrate and myeloperoxidase levels in the mouse pleurisy induced by carrageenan," Peptides, vol. 20, no. 8, pp. 949-956, 1999.

[30] Y. Sakaguchi, H. Shirahase, K. Kunishiro, A. Ichikawa, M. Kanda, and Y. Uehara, "Effect of combination of nitric oxide synthase and cyclooxygenase inhibitors on carrageenaninduced pleurisy in rats," Life Sciences, vol. 79, no. 5, pp. 442447, 2006.

[31] D. Salvemini, P. Z. Manning, B. S. Zweifel et al., "Dual inhibition of nitric oxide and prostaglandin production contributes to the antiinflammatory properties of nitric oxide synthase inhibitors," The Journal of Clinical Investigation, vol. 96, no. 1, pp. 301-308, 1995.

[32] L. Sautebin, A. Ialenti, A. Ianaro, and M. di Rosa, "Relationship between nitric oxide and prostaglandins in carrageenin pleurisy," Biochemical Pharmacology, vol. 55, no. 7, pp. 1113-1117, 1998.

[33] H. Sano, T. Hla, J. Maier et al., "In vivo cyclooxygenase expression in synovial tissues of patients with rheumatoid arthritis and osteoarthritis and rats with adjuvant and streptococcal cell wall arthritis," The Journal of Clinical Investigation, vol. 89, no. 1, pp. 97-108, 1992.

[34] R. M. Clancy and S. B. Abramson, "Nitric oxide: a novel mediator of inflammation," Proceedings of the Society for Experimental Biology and Medicine, vol. 210, no. 2, pp. 93-101, 1995.

[35] H. F. Mcgarry, L. D. Plant, and M. J. Taylor, "Diethylcarbamazine activity against Brugia malayi microfilariae is dependent on inducible nitric-oxide synthase and the cyclooxygenase pathway," Filaria Journal, vol. 4, article 4, 2005.

[36] F. A. J. van de Loo, O. J. Arntz, and W. B. van den Berg, "Effect of interleukin 1 and leukaemia inhibitory factor on chondrocyte metabolism in articular cartilage from normal and interleukin6-deficient mice: role of nitric oxide and IL-6 in the suppression of proteoglycan synthesis," Cytokine, vol. 9, no. 7, pp. 453-462, 1997.

[37] S. Cuzzocrea, B. Zingarelli, P. Hake, A. L. Salzman, and C. Szabo, "Antiinflammatory effects of mercaptoethylguanidine, a combined inhibitor of nitric oxide synthase and peroxynitrite scavenger, in carrageenan-induced models of inflammation," Free Radical Biology and Medicine, vol. 24, no. 3, pp. 450-459, 1998. 


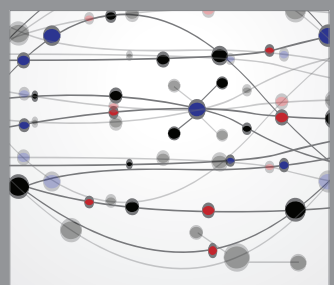

The Scientific World Journal
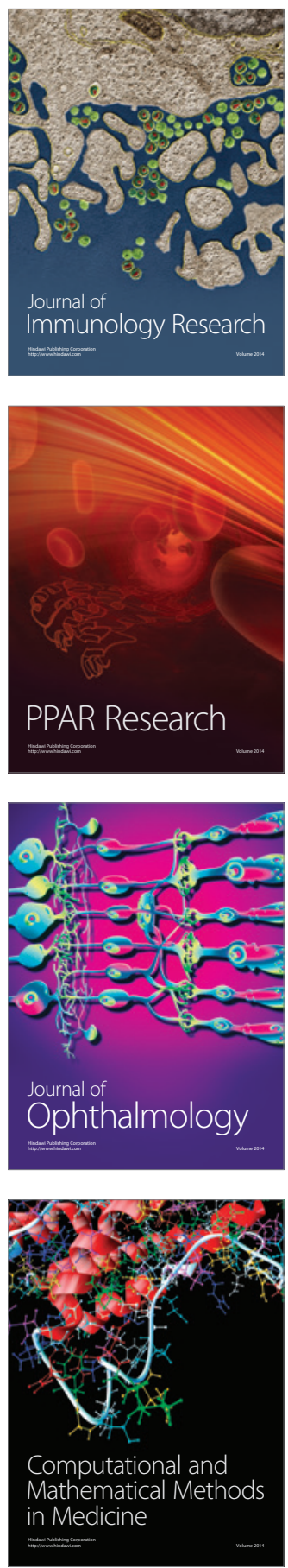

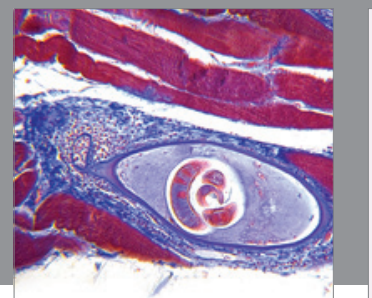

Gastroenterology

Research and Practice
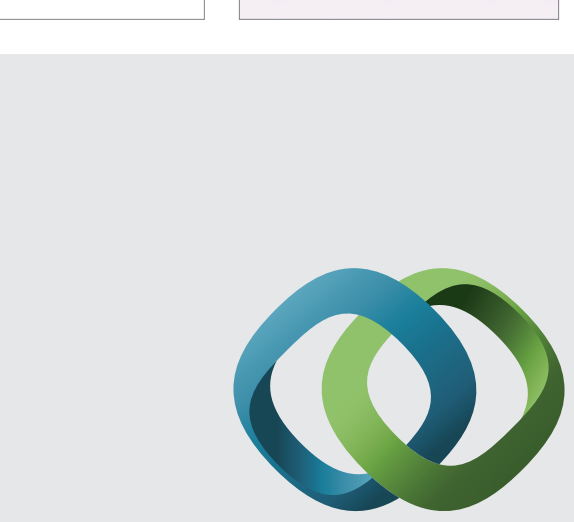

\section{Hindawi}

Submit your manuscripts at

http://www.hindawi.com
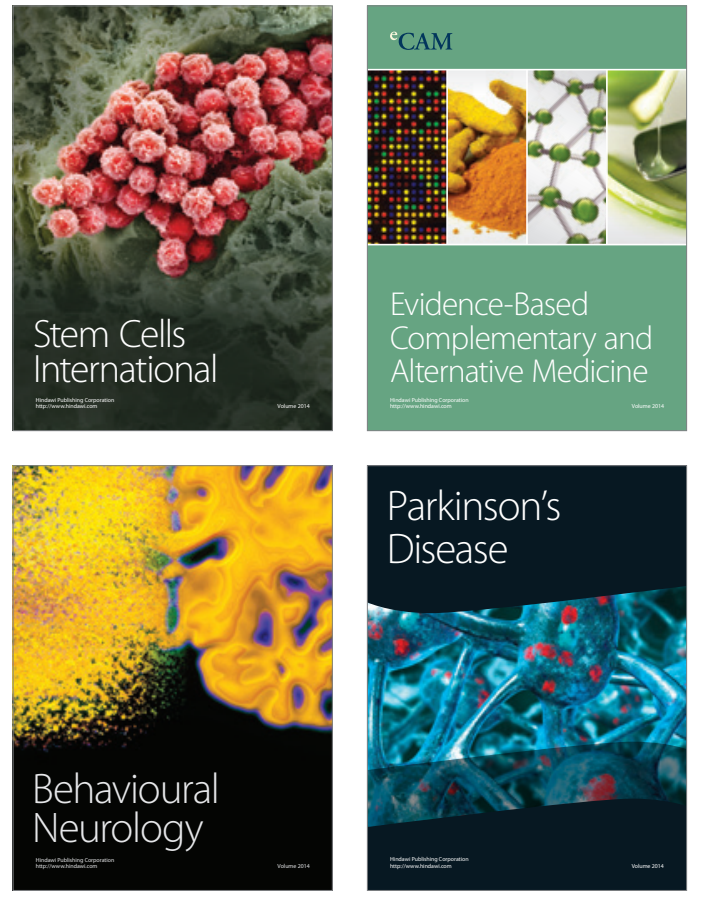
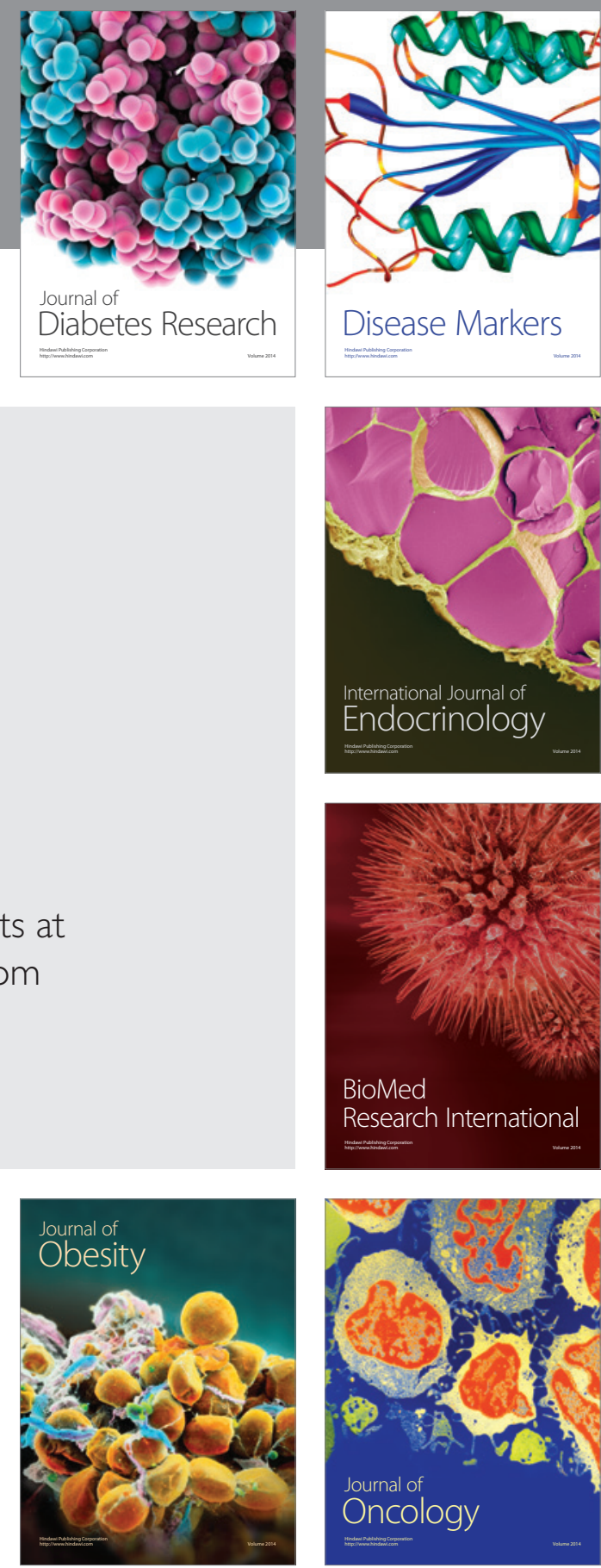

Disease Markers
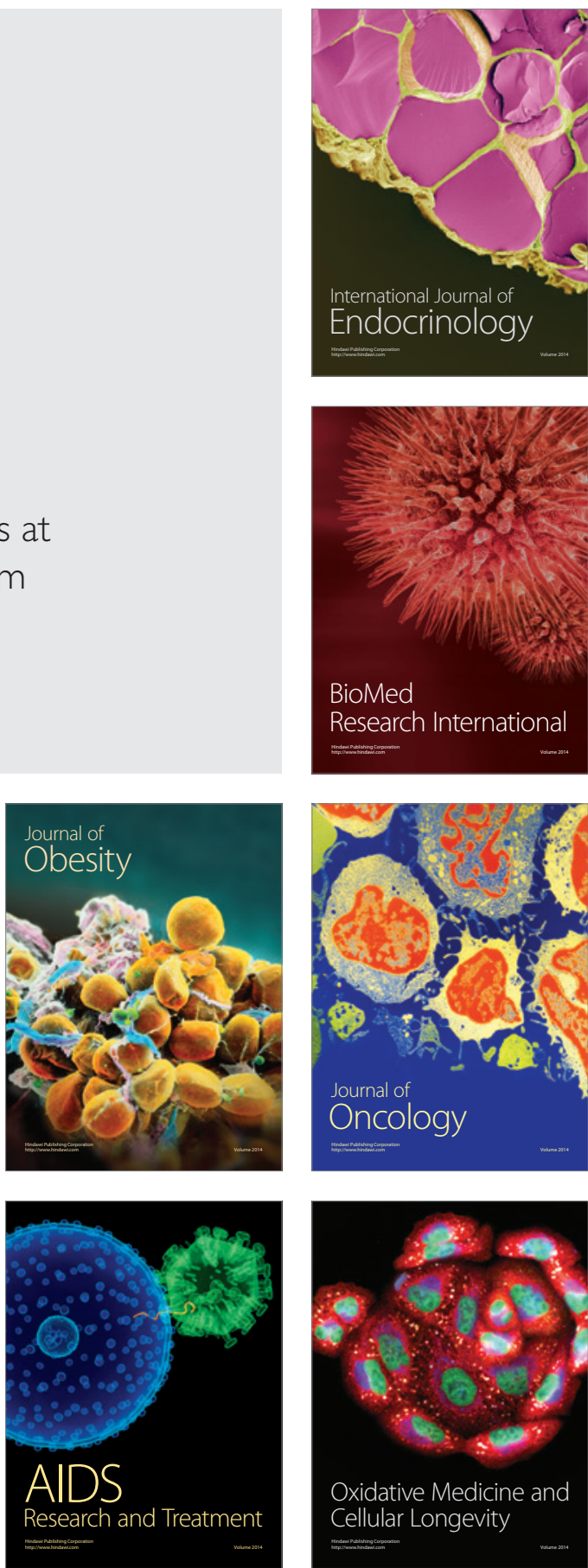